\title{
Effects of hormone therapy on quality of life in postmenopausal women with CAD differed according to menopausal symptoms
}

\author{
Hlatky MA, Boothroyd D, Vittinghoff E, et al, for the HERS Research Group. Quality of life and depressive symptoms in \\ postmenopausal women after receiving hormone therapy: results from the Heart and Estrogen/Progestin Replacement \\ Study (HERS) trial.JAMA 2002 Feb 6;287:591-7.

\section{QUESTION: Does hormone therapy $(\mathrm{HT})$ improve health-related quality of life (HRQL) in postmenopausal women with coronary artery disease (CAD)?}

\section{Design}

Randomised \{allocation concealed*\} $\dagger$, blinded \{patients, clinicians, data collectors, and outcome assessors $\} \ddagger^{*}$, placebo-controlled trial with follow up to 3 years.

\section{Setting}

Outpatient and community settings at 20 US clinical centres.

\section{Patients}

2763 postmenopausal women $<80$ years of age (mean age $67 \mathrm{y}$ ) with documented CAD (previous myocardial infarction $[\mathrm{MI}],>50 \%$ luminal narrowing of a major vessel on angiography, or a previous coronary revascularisation procedure). Exclusion criteria were MI or revascularisation procedure in the past 6 months, previous hysterectomy, contraindications to HT, HT in the previous 3 months, or life-threatening illness. 2762 patients (99.9\%) were included in the analysis; 2246 $(81 \%)$ had HRQL data for all time points (baseline, 4 mo, 1 y, and 3 y).

\section{Intervention}

1380 women were allocated to HT $(0.625 \mathrm{mg}$ of conjugated equine oestrogens and $2.5 \mathrm{mg}$ of medroxyprogesterone acetate [Prempro, Wyeth Ayerst, Radnor, PA, USA]), and 1383 were allocated to placebo.

\section{Main outcome measures}

HRQL questionnaires assessing physical function (Duke Activity Status Index), energy or fatigue (4-item RAND scale), mental health (RAND Mental Health Inventory), and depressive symptoms (8-item scale by Burnam and colleagues).

\section{Main results}

Analysis was by intention to treat. At 3 years, scores for physical function and energy or fatigue declined progressively in both groups. Women who received HT had faster reductions in physical function and a trend toward faster declines in energy or fatigue scores but had greater improvements in depressive symptoms than did women who received placebo. The groups did not differ for mental health.

Subgroup analysis based on presence of flushing at baseline showed that women with flushing $(\mathrm{n}=434)$ who received HT had improved mental health and depressive symptoms over 3 years but did not differ from those who received placebo for physical function or energy or fatigue. Women with no flushing $(\mathrm{n}=2325)$ who received HT had greater declines in physical function and energy but did not differ for mental health or depressive symptoms from those who received placebo.

\section{Conclusions}

In postmenopausal women with coronary artery disease, hormone therapy reduced physical function and energy but improved depressive symptoms overall. Hormone therapy improved emotional quality of life in women with flushing symptoms, but reduced physical quality of life in women with no flushing symptoms.

*See glossary.

†Hulley S, Grady D, Bush T, et al.JAMA 1998;280:605-13.

$\ddagger$ Information provided by author.

A modified version of this abstract also appears in Evidence-Based Mental Health and Evidence-Based Nursing.

Source of funding: Wyeth-Ayerst Research

For correspondence: Dr MA Hlatky,

Stanford University, School of Medicine, Stanford, CA, USA.

E-mail

hlatky@stanford.edu

Hormone therapy $v$ placebo for postmenopausal women with coronary artery disease

\begin{tabular}{llll} 
& All patients & \multicolumn{1}{c}{$\begin{array}{c}\text { Patients with } \\
\text { flushing }\end{array}$} & $\begin{array}{c}\text { Patients with no } \\
\text { flushing }\end{array}$ \\
\cline { 2 - 4 } Outcomes at 3 years & $\begin{array}{l}\text { Mean change in scores } \\
\text { (hormone therapy v placebo, } p \text { value) }\end{array}$ & \\
Physical function & $-4.4 v-3.1 \S$ & $3.1 v-2.2, p=0.42$ & $-4.2 v-3.3,=0.04$ \\
\hline Energy or fatigue & $-4.6 v-3.0 \S$ & $2.3 v-2.4, p=0.99$ & $4.6 v-3.1, p=0.03$ \\
\hline Mental health & $0.2 v-0.9 \S$ & $2.6 v-0.5, p=0.04$ & $-0.06 v-1.1,=0.40$ \\
\hline Depressive symptoms & $\begin{array}{l}\text { No data } \\
\text { available }\end{array}$ & $-0.5 v 0.007, p=0.1$ & $-0.08 v 0.06,=0.08$ \\
\hline
\end{tabular}

$\S p$ values not reported. Scales for physical function ranged from 0 (worst) to 58.2 ; energy or fatigue and mental health scores ranged from 0 (worst) to 100; and depression ranged from 4 (worst) to -8.2 .

\section{COMMENTARY}

The study by Hlatky et al is important because of its large sample size and the paucity of existing research on quality of life in postmenopausal women, especially as it pertains to HT. The results suggest that HT improves quality of life only for women with menopausal symptoms and does not generally benefit postmenopausal women with heart disease. Presence or absence of hot flushing seemed to be the defining factor in improvement of depressive symptoms. Women with flushing who received HT also had lower quality of life scores at baseline. Physical illness, chest pain, and education level had an even greater negative effect on quality of life than did HT.

What factors need to be considered before applying these results to other patients? Participants apparently were not screened for smoking, which is known to interact with HT. Participants had a mean age of 67 years, whereas the detrimental effects of menopause are known to occur within the first few years after cessation of menses. Hlatky $e t$ al noted that women with flushing symptoms who improved on HT tended to be much younger. Progesterone is sometimes said to be an"anti-oestrogen,"so would similar results be obtained in a study of unopposed oestrogen or of HT in women having surgical menopause? Some clinicians also claim that oral and transdermal therapies have different effects, in that transdermal oestrogen does not give the full benefit of lowering cholesterol and may compromise the benefits of HT.

The findings of Hlatky et al suggest that HT does not reverse preexisting CAD in postmenopausal women. The effects of HT in preventing CAD in younger, perimenopausal women are unknown. The findings also suggest that oestrogen improves depressive symptoms in postmenopausal women, especially those with flushing symptoms. However, given recent findings showing an increased risk for cancer and heart disease for women on $\mathrm{HT}^{1}$ the role of oestrogen needs to be reassessed.

Manatee Glenns Bradenton, Florida, USA

1 Writing Group for the Women's Health Initiative Investigators. Risks and benefits of Women's Health Initiative Randomized Controlled Trial. JAMA 2002;288:321-33. 